\title{
O Laboratório de Educação Matemática e as suas potencialidades lúdico- pedagógicas: algumas experiências itinerantes
}

The Mathematical Education Laboratory and its ludic-pedagogical potentialities: some itinerant experiences

El Laboratorio de Educación Matemática y sus potencialidades lúdico-pedagógicas: algunas experiencias itinerantes

Recebido: 05/02/2021 | Revisado: 08/02/2021 | Aceito: 09/02/2021 | Publicado: 15/02/2021

\author{
Américo Junior Nunes da Silva \\ ORCID: https://orcid.org/0000-0002-7283-0367 \\ Universidade do Estado da Bahia, Brasil \\ E-mail: ajnunes@uneb.br \\ Ilvanete dos Santos de Souza \\ ORCID: https://orcid.org/0000-0001-6036-834X \\ Universidade Federal da Bahia, Brasil \\ E-mail: ilvanetess@gmail.com \\ Simone Silva da Fonseca \\ ORCID: https://orcid.org/0000-0001-7365-1451 \\ Universidade Federal de Sergipe, Brasil \\ E-mail: simonefonsecasilva@ hotmail.com
}

\begin{abstract}
Resumo
Este texto propõe-se a discutir a implantação do Laboratório Itinerante para o Ensino e Aprendizagem de Matemática (LIEAM), vinculado ao Departamento de Ciências Humanas da Universidade do Estado da Bahia, Campus IX, e as suas implicações para os movimentos de ensino e aprendizagem da Matemática. O objetivo do LIEAM é despertar a curiosidade e o interesse dos estudantes do Ensino Fundamental pela Matemática, a partir do uso de jogos, enigmas e outros dispositivos potencialmente lúdicos; além de promover, por meio da relação entre universidade e escola, um ambiente de estudo, ensino, pesquisa e extensão mediatizado pelas ações itinerantes. As análises possibilitam observar que espaços de experimento como este tem relevante papel na formação do professor que ensina Matemática, uma vez que a condução desse espaço pauta-se na (re)significação de sua prática pedagógica. Por outro lado, no que tange aos movimentos de ensino e aprendizagem dessa ciência, fica perceptível uma aproximação dos estudantes envolvidos com a Matemática, o que contribui para uma desmistificação da imagem dessa ciência como difícil e pouco acessível.
\end{abstract} Palavras-chave: Laboratório de educação matemática; Formação de professores; Metodologia; Ensino; Aprendizagem.

\begin{abstract}
This text is intended to be discussed in the implementation of the Itinerant Laboratory for the Teaching and Learning of Mathematics (LIEAM), linked to the Department of Human Sciences of the University of the State of Bahia, Campus IX, and its implications for the teaching and learning movements da Mathematics. The objective of LIEAM is to awaken the curiosity and interest of two students of Fundamental Education in Mathematics, from the use of games, enigmas and other potentially playful devices; Besides promoting, through the relationship between the university and the school, a study environment, teaching, research and mediated extension for itinerant activities. As analyzes, it is possible to observe that experiment spaces such as this relevant topic role in the formation of a teacher who teaches Mathematics, one time that the conduction of this space is (re) significance of their pedagogical practice. On the other hand, not that it has years of teaching and learning movements from science, is perceptible about an approach two students involved in Mathematics, or that it contributed to a demystification of the image of science as difficult and little accessible.
\end{abstract}

Keywords: Mathematics education laboratory; Teacher training; Methodology; Teaching; Learning.

\section{Resumen}

Este texto tiene como objetivo discutir la implantación del Laboratorio Itinerante para la Enseñanza y Aprendizaje de las Matemáticas (LIEAM), vinculado al Departamento de Ciencias Humanas de la Universidad Estadual de Bahía, Campus IX, y sus implicaciones para los movimientos de enseñanza y aprendizaje de las Matemáticas. . El objetivo de LIEAM es despertar la curiosidad e interés de los alumnos de Primaria por las Matemáticas, mediante el uso de juegos, rompecabezas y otros dispositivos potencialmente lúdicos; además de promover, a través de la relación 
universidad-escuela, un ambiente de estudio, docencia, investigación y extensión mediado por acciones itinerantes. Los análisis permiten observar que espacios experimentales como éste tienen un papel importante en la formación del docente que enseña Matemáticas, ya que la conducción de este espacio se fundamenta en la (re) significación de su práctica pedagógica. Por otro lado, en lo que respecta a los movimientos de enseñanza y aprendizaje de esta ciencia, se nota una aproximación de los estudiantes involucrados en Matemáticas, lo que contribuye a desmitificar la imagen de esta ciencia como difícil e inaccesible.

Palabras clave: Laboratorio de educación matemática; Formación de profesores; Metodología; Enseñando; Aprendizaje.

\section{Introdução}

Os conteúdos abordados pelos professores ao longo da Educação Básica, sobretudo no Ensino Fundamental, constituise de grande importância social, tendo em vista que se tratam de conceitos-chave para o movimento de letramento matemático, com grande implicação desses conceitos para o entendimento das diferentes situações cotidianas e a constituição cidadã, como evidenciam os Referenciais Curriculares do Estado da Bahia (Bahia, 2019).

Embora muitos estudantes sejam levados, ao longo de suas vivências escolares realizadas na Educação Básica, a acreditarem no contrário do que dissemos no parágrafo anterior, percebendo a Matemática como difícil e pouco acessível; compreendemos, respaldando-se em Machado (1989) e Silva, Souza e Prado (2020), que não existe uma Matemática teórica e outra prática e, sobretudo, que precisamos ter cuidado para, enquanto docente, não apresentá-la desarticulada aos estudantes. Ainda segundo os autores é necessário compreender os mecanismos que vinculam o conhecimento matemático à realidade. Temos aqui, portanto, um desafio posto aos educadores e educadoras matemáticas: (re)significar essas percepções e aproximar o estudante do conhecimento matemático, percebendo a sua ligação com o dia a dia. Isso, de certa forma, nos faz olhar para a área de formação de professores que ensinam Matemática e os diferentes saberes necessários à docência.

Para Tardif (2011, p. 18), o "saber dos professores é plural, compósito, heterogêneo, por que envolve no próprio exercício do trabalho, conhecimentos e um saber fazer bastante diverso, proveniente de fontes variadas e provavelmente de natureza diferenciada". São nas diferentes vivências promovidas nos espaços de formação que esses saberes são (re)significados; daí a importância da formação inicial e continuada, seja ela institucionalizada de forma pontual ou diversa; promovidas pelos grupos de estudos, eventos dentre outros.

Nessa direção, entendemos que os saberes docentes não são estáticos e estagnados; pelo contrário, eles se encontram em constantes transformações, de acordo com as exigências específicas das situações concretas do seu cotidiano profissional. O professor tem que ter consciência da sua importância para transformar a realidade propiciando condições para que os alunos se constituam como sujeitos de sua própria aprendizagem, como evidenciaram Vieira e Silva (2020).

Nos anos iniciais do Ensino Fundamental são introduzidos e trabalhados conceitos fundamentais da Matemática. No entanto, muitos dos alunos ingressam no segundo segmento do Ensino Fundamental, sem compreender conceitos das estruturas aditivas e multiplicativas, por exemplo, o que coloca às instituições formadoras de professores polivalentes o desafio de buscar soluções e sanar essas dificuldades. Nessa direção, Justo e Dorneles (2012) defendem que

O professor polivalente em formação precisa modificar as suas crenças e sentimentos ruins em relação à matemática, rompendo com saberes adquiridos durante a sua trajetória estudantil. Um professor que gosta e conhece o objeto de ensino, mais facilmente ensina, e o seu aluno, possivelmente, aprende mais (Justo; Dorneles, 2012, p. 94).

Dessa forma, partindo do que nos apresentaram os autores anteriormente referenciados e também de Silva (2021), podemos pensar que a prática e metodologia do professor podem contribuir de maneira positiva para os processos de ensino e aprendizagem da Matemática. Partindo dessa reflexão sobre os conhecimentos do professor, sabe-se que ensinar e aprender Matemática não devem se restringir aos muros escolares, nem as instruções específicas do conteúdo; eles precisam acontecer por meio das relações constituídas na sociedade e em seu processo histórico e cultural, em um movimento de constituição e 
resolução de problemas (Nascimento; Souza \& Silva, 2020). Ainda segundo os autores, na matemática os processos de ensino e aprendizagem precisam se constituir no cotidiano e com as potencialidades do desenvolvimento do raciocínio lógico.

O Laboratório de Educação Matemática (LEM), como são comumente conhecidos dentro de uma instituição de ensino, é visto como um ambiente potencializador da aprendizagem de alunos e futuros professores, e pode ser visto também como um agente de mudanças num ambiente onde se concentram pesquisas na busca de novas alternativas e metodologias de ensino, como evidenciou Silva (2020a) e Silva (2020b). Esse espaço, ainda partindo do que apresentou o autor anteriormente referenciado, permite ao professor vislumbrar uma aprendizagem com significado, entendendo que alguns dispositivos potencialmente lúdico-pedagógicos são importantes no movimento de construção do conhecimento matemático. Nessa perspectiva, Sousa e Rolim (2013) enfatizam que:

O laboratório de matemática pode ser o espaço promotor de articulações entre o conteúdo sistematizado e o lúdico, com representações visuais e táteis, subsidiando a problematização dos conceitos matemáticos estreitando as relações de interesse pela matemática tanto por parte dos professores como pelos alunos, com o sentido de integrar os estudos teóricos, metodológicos e práticos (Sousa; Rolim, 2013, p. 6).

O LEM é um espaço potencialmente promotor de vivências lúdicas, ao potencializar, através de materiais concretos e digitais, a interação e o movimento pendular que intercruza a teoria e a prática. A depender da forma como é conduzido pode se distanciar de práticas lineares e, muitas vezes, sem significados, algo ainda muito comum nas escolas da Educação Básica.

Para tratar teoricamente sobre o LEM recorremos, inicialmente, a Lorenzato (2006) e Silva (2014). De acordo com estes pesquisadores existem distintos entendimentos sobre o que é um LEM, sendo que de um ponto de vista mais reducionista o LEM pode ser um depósito/arquivo de instrumentos onde seriam guardados materiais essenciais, tornando-os acessíveis para as aulas, tais como: livros, materiais manipuláveis, computadores, filmes, entre outros; inclusive matérias-primas e instrumentos para confeccionar materiais didáticos. Além disso, o LEM pode ser concebido como uma biblioteca ou um museu de Matemática.

Lorenzato (2006), nesse ínterim, afirma que o conceito de LEM é muito amplo, pois é,

[...] uma sala-ambiente para estruturar, organizar, planejar e fazer acontecer o pensar matemático, é um espaço para facilitar, tanto ao aluno como ao professor, questionar, conjecturar, procurar, experimentar, analisar e concluir, enfim, aprender e principalmente aprender a aprender (Lorenzato, 2006, p. 7).

Desta forma, o LEM passa a ser um local de referência nas escolas de Educação Básica e, principalmente, no ensino fundamental, pois os professores podem planejar aulas, realizar reuniões, organizar e dinamizar outras atividades como exposições, feiras de ciências, olimpíadas, jogos, avaliações, entre outros (Lorenzato, 2006).

O LEM, também, pode constituir-se, ainda, como espaço adequado para promover a formação inicial ou continuada de professores que ensinam matemática, com atividades relacionadas às disciplinas de prática de ensino, bem como a realização de oficinas pedagógicas, propiciando ao futuro docente ou ao professor, reflexões e experiências sobre os pressupostos do ensino e da aprendizagem em Matemática, alicerçados em tendências metodológicas da educação matemática (Lopes \& Araújo, 2007). Um ponto importante a ser considerado é a percepção desse espaço de formação como desencadeador de conhecimentos que são, também, necessários à docência: o conhecimento lúdico e o conhecimento lúdico e pedagógico do conteúdo (Silva, 2020c).

Segundo Turrioni \& Perez (2009) o LEM caracteriza-se como um lugar diferenciado da sala de aula onde se permite que os alunos possam trabalhar informalmente, movimentar-se, discutir, escolher materiais e métodos, procurando a solução dos problemas com autonomia, algo, que ao nosso ver, precisaria ser feito, também, durante as aulas.

Franzoni e Panossian (1999) destacam que a existência de um espaço físico para o laboratório não é tão imprescindível quanto o conceito de laboratório. É necessário refletir sobre o seu valor como espaço estruturado e lúdico, que 
lida com regras, conceitos, e fórmulas, que possibilita a brincadeira, o jogo e a experimentação, e que deve ser amplamente discutido entre o grupo de professores e alunos da escola. (Franzoni \& Panossian, 1999).

Desse modo, entendemos que a concepção de LEM não se restringe apenas a uma sala onde são armazenados ou produzidos recursos didáticos, mas sim, uma alternativa metodológica para os processos de ensino e aprendizagem da Matemática (Franzoni \& Panossian, 1999). Nesse sentido, cabe ressaltar que assumir a concepção de que o LEM é uma alternativa metodológica não impede que se organize, na instituição escolar, um espaço adequado para o laboratório de ensino, como defende Lorenzato (2006) e Silva (2014).

Nessa perspectiva implantamos, por meio de proposta que articula os cursos de Licenciatura em Matemática e Pedagogia da Universidade do Estado da Bahia (UNEB), Campus IX, e uma escola municipal de Ensino Fundamental na cidade de Barreiras-BA, o Laboratório Itinerante de Ensino e Aprendizagem de Matemática (LIEAM). Preliminarmente, um contato inicial permitiu construir algumas impressões iniciais, são elas que nos incitaram a construção deste trabalho.

Cabe ressaltar que realizamos, em outros momentos, atividades de extensão com professores e futuros professores que ensinam matemática nos anos iniciais e finais do Ensino Fundamental, e a partir delas inferimos algumas problemáticas que nos motivaram, também, para a construção dessa proposta. Muitos estudantes, por exemplo, chegam à universidade com uma imagem negativa sobre a Matemática e não a (re)significa, o que, muitas vezes, implica negativamente no processo de ensino e aprendizagem quando professores. Entendemos o processo de formação da identidade docente como algo que não acontece exclusivamente a partir da formação inicial, pelo contrário, as vivências que acontecem antes de seu ingresso no curso de graduação, principalmente quando alunos, são marcantes e precisam ser consideradas (Silva \& Passos, 2019).

A ausência de estrutura física em parte considerável das escolas da rede municipal que contemple uma sala ambiente destinada ao laboratório, seja ela de Matemática ou multidisciplinar, são um dos crivos que conduzem/justificam essa proposta de extensão. Este trabalho, partindo de todas essas vivências, vem relatar como se deu a implantação do LIEAM, algumas experiências desenvolvidas e os resultados.

Contudo, o objetivo dessa proposta foi constituir um espaço itinerante de ensino e aprendizagem da Matemática, de forma a despertar a curiosidade e o prazer dos estudantes por essa ciência, a partir do uso de jogos, enigmas e outros dispositivos lúdico-pedagógicos. As experiências que serão aqui relatadas aconteceram em uma escola pública de Ensino Fundamental em um município do interior do Estado da Bahia, com os alunos do $5^{\circ}, 7^{\circ}$ e $8^{\circ}$ anos. Nesse projeto piloto com duração de três meses, foram envolvidos 25 alunos por turma e os 3 professores que ensinam Matemática.

\section{Metodologia}

O LIEAM é um projeto de extensão que se caracteriza como uma ação itinerante ao romper com a concepção de tempos e espaços pontuais de ensino e aprendizagem da Matemática. Tem como público-alvo professores que ensinam Matemática no ensino fundamental em escolas públicas de um município do interior do Estado da Bahia, estudantes do curso de Licenciatura em Matemática e Pedagogia e alunos da Educação Básica. Nessa fase da implantação do LIEAM optamos por aplicar 30 jogos artesanais, construídos pelos estudantes da licenciatura, cujo objetivo era que estimulavassem o raciocínio lógico matemático; além de uma "caixa matemática" composta por jogos confeccionados com material de baixo custo e que contemplavam conceitos referente as quatro operações fundamentais. Em um primeiro momento, com a participação de todos os envolvidos, realizamos encontros para a tabulação, categorização e exploração dos jogos que compõem essa fase do projeto.

Concomitantemente, foi constituído um grupo de estudo colaborativo, com a participação dos estudantes da licenciatura e os professores da escolas parceiras que se interessarem pela formação, possibilitando a reflexão e o desenvolvimento de diferentes olhares e significações sobre o trabalho e a vida docente. Segundo Pacheco e Flores (1999, p. 135) “a formação contínua deve potencializar a colaboração dos diversos atores do sistema educativo e a realização de projetos 
de investigação-ação-formação orientados para o desenvolvimento profissional do professor".

Após esses momentos iniciais de estudo e apropriação dos materiais foram realizadas exposições/visitas pedagógicas pré-agendadas nas escolas da Educação Básica do referido município. Durante as exposições dos recursos didáticos realizamos atividades potencialmente lúdicas, que envolveram conceitos matemáticos, estimulando a participação orientada dos alunos. A cada visita foram disponibilizadas fichas de avaliação/autoavaliação para os alunos se posicionarem sobre as atividades propostas e avaliarem as suas experiências.

A implementação do LIEAM aconteceu em uma escola piloto que atende estudantes dos Anos Iniciais e Finais do Ensino Fundamental, e foi organizada em três etapas. Apresentadas a seguir:

Primeira etapa: Definição da escola piloto. O critério adotado para a escolha da escola foi apresentar os piores resultados nas avaliaçãoes externas; uma vez que a nossa tentativa era contribuir, mesmo que a longo prazo, com a melhoria desses resultados. Logo após a escolha e convidado o grupo de professores, foi aplicado um questionário diagnóstico com intuito de conhecer o perfil e as concepções desses docentes acerca da ludicidade e suas implicações para o ensino e aprendizagem da Matemática.

Com base nos dados produzidos, alinhamos a proposta inicialmente construída para atender as especificidades da escola parceira, pois nosso intuito é que a proposta pedagógica do LIEAM atenda a uma perspectiva de formação continuada para os professores que aceitaram participar desse projeto de extensão.

Segunda etapa: Foi definido um cronograma de trabalho com base nas vivências da sala de aula do professor parceiro, como a construção de recursos para composição do LIEAM na escola, por exemplo; validação dos recursos produzidos com os próprios alunos; discussão/reflexão das experiências de validação realizada em sala de aula, com a participação dos professores; sistematização de sequências didáticas que contemplem os materiais produzidos e os conteúdos matemáticos abordados; e produção de outros materiais pelos professores.

Terceira etapa: A realização de uma pesquisa de acompanhamento da práxis na sala de aula, que consistiu no distanciamento dos formadores-pesquisadores da escola, com o intento de possibilitar autonomia aos professores no uso e construção de recursos com potencial lúdico. Esses dados foram produzidos a partir do uso de entrevista, aplicação de questionário e observações aleatórias das turmas dos professores parceiros.

Pretendemos com essa proposta de formação, difundir o LIEAM para outras escolas da Rede Municipal de ensino do Estado da Bahia e de todo o Brasil. Vale salientar que todas as etapas precisam ser acompanhadas e ter a participação de estudantes da licenciatura, futuros professores.

Vale ressaltar que, concomitante a realização da proposta de formação, foram agendadas e realizadas as visitas/exposições pedagógicas, de no mínimo uma a cada mês. Em tempo, reforçamos que antes da realização de qualquer atividade os formadores-pesquisadores e monitores se reuniram para o planejamento das atividades a serem desenvolvidas.

O LIEAM, portanto, constitui-se uma sala-ambiente de construção coletiva de conhecimento matemático, no qual os recursos didáticos vão aproximar os estudantes do objeto matemático, ressignificando as percepções que muitos têm dessa ciência. Com este espaço os professores que ensinam matemática, a partir do uso destes recursos, poderão dinamizar seu trabalho e enriquecer as atividades de ensino e aprendizagem, tornando esse processo mais prazeroso, além de dar mais vazão à criatividade dos alunos.

Desse modo, a inclusão de atividades dessa natureza nas escolas públicas pode ser uma das vertentes fundamentais como modo de conseguir uma melhor qualidade na aprendizagem da Matemática. Pois, mais do que obter um bom 
desempenho em exercícios pré-definidos, ou a memorização de fórmulas, um dos objetivos centrais do ensino da Matemática é fazer com que os alunos desenvolvam uma compreensão aprofundada dos conceitos matemáticos. Através dessa compreensão, os alunos poderão ser capazes de conseguir o que se denomina como pensamento avançado.

O projeto consiste na realização de diversas atividades, dentre as quais a principal é a utilização de jogos e materiais concretos que envolvem conceitos matemáticos às turmas de alunos da escola básica, acompanhados de seus professores, ou grupos de professores. Um dos objetivos dessas atividades é despertar o interesse dos alunos pela Matemática de uma forma alternativa àquela geralmente utilizada em sala de aula. Além disso, os professores participantes serão estimulados a reproduzir os jogos utilizados nas visitas e a incorporá-los como mais um instrumento de metodologia de ensino com o intuito de facilitar o aprendizado do aluno.

As análises preliminares possibilitam observar que espaços de experimentos como estes, tem relevante papel na formação docente. Destaca-se, também, a importância desse espaço de formação à medida que possibilita aos professores o questionamento de seu fazer docente e instiga o aprofundamento do conhecimento matemático significativo no cotidiano.

\section{Resultados e Discussão}

Com a implementação do LIEAM tivemos duas experiências. A primeira experiência foi com a exposição dos jogos do LIEAM em um evento acadêmico promovido pela Universidade do Estado da Bahia. Os acadêmicos, principalmente, os do curso de licenciatura em Matemática, demonstraram bastante interesse pelos jogos, acharam muito interessante à iniciativa do projeto. Também, encontraram dificuldades em solucionar os problemas propostos pelos jogos, porém, mesmo assim não se sentiram desestimulados a encontrar a solução, insistindo por períodos longos de tempo. Além disso, pudemos perceber que se sentiram estimulados a implementar a utilização de jogos na sua futura prática pedagógica. Smole (2007, p. 9) afirma que "o trabalho com jogos nas aulas de matemática, quando bem planejado e orientado, auxilia o desenvolvimento de habilidades como observação, análise, levantamento de hipóteses, busca de suposições, reflexão, tomada de decisão, argumentação e organização".

A segunda experiência foi em uma escola de Ensino Fundamental do município, com os alunos do $5^{\circ}, 7^{\circ}$ e $8^{\circ}$ anos e foi a que causou maior impacto, pois, os estudantes têm uma grande dificuldade na aceitação dos novos métodos de ensino. Encontramos certa resistência, pois, muitos alunos, como eles mesmo disseram: "não gostam de pensar". Para tentar amenizar essa resistência, buscamos estimular os alunos a manusear os jogos que despertassem maior interesse. Na Figura 1 podemos visualizar o espaço do refeitório da escola onde aconteceu as exposições e manipulações dos jogos. 
Figura 1 - Refeitório da escola onde aconteceu as manipulações dos jogos.

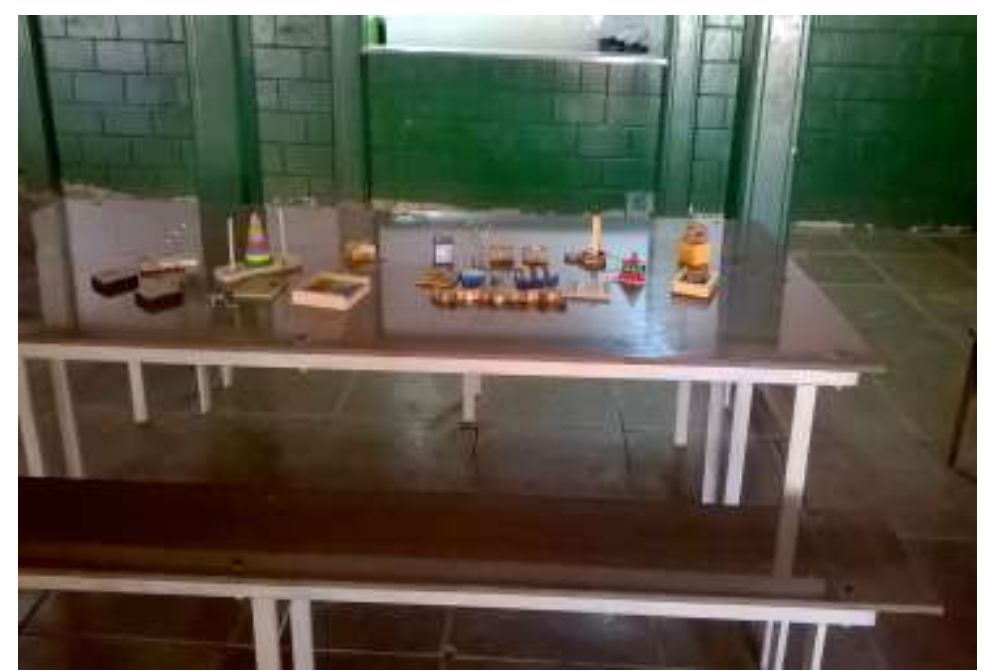

Fonte: Projeto de extensão LIEAM.

$\mathrm{Na}$ Figura 2 podemos perceber os alunos manipulando os jogos, saindo da rotina diária da sala de aula, trocando informações, se socializando e interagindo entre os pares.

Figura 2 - Alunos do $7^{\circ}$ ano realizando a manipulação dos jogos.

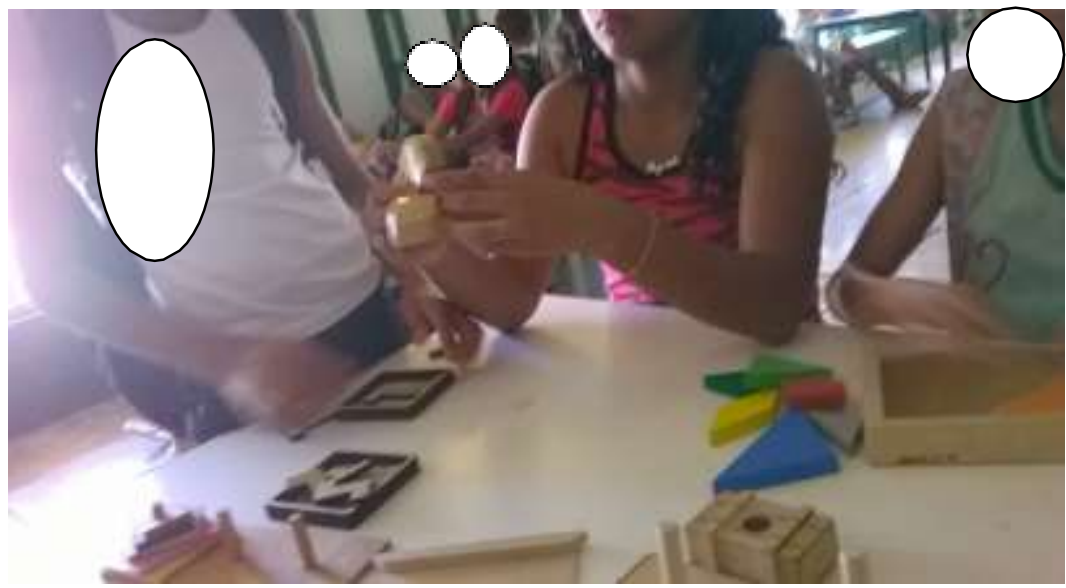

Fonte: Projeto de extensão LIEAM.

Apesar de alguns alunos não se mostrarem empenhados para manusear os jogos, com o passar do tempo começaram a demonstrar um certo interesse. Como afirma Grando (2004, p.19)" É no jogo e pelo jogo que a criança é capaz de atribuir aos objetos mediante sua ação lúdica, significados diferentes; desenvolver a sua capacidade de abstração e começar a agir independentemente daquilo que vê". O projeto tomou dimensões muito maiores do que o que foi proposto, pois ultrapassou os portões da escola. Alguns alunos levaram o problema para casa, voltando com a resposta de alguns jogos, mesmo isso não sendo colocado como tarefa para eles.

Constatamos também a grande dificuldade dos alunos para solucionar os desafios propostos pelos jogos do LIEAM, pois muitos, simplesmente, não sabiam efetuar operações básicas de matemática. Essas dificuldades reforçam a importância desse projeto como uma possibilidade de diminuir bloqueios apresentados por muitos alunos que sentem-se incapacitados para aprender matemática. 


\section{Conclusão}

Dessa forma, podemos concluir que a implantação do Laboratório Itinerante para o Ensino e Aprendizagem de Matemática (LIEAM), trás nessa ação muitos desafios que perpassam desde espaços para o desenvolvimento dessa prática até as questões de ensino de matemática. Embora, nosso objetivo foi despertar a curiosidade e o interesse dos estudantes do Ensino Fundamental pela Matemática, a partir do uso de jogos, enigmas e outros dispositivos potencialmente lúdicos percebemos alguns entraves nesse processo sinalizado pela resistência dos estudantes em manipular jogos que exigiam conceitos mais complexos.

Outro ponto que merece destaque é a relação entre universidade e escola, possibilitada pela extensão entre esses dois espaços. Pois ainda é perceptível principalmente nas escolas da periferia a necessidade de ações que possibilite um ambiente de estudo, ensino, pesquisa e extensão mediatizado pelas ações itinerantes.

As análises possibilitaram observar que espaços de experimento como este tem relevante papel na formação do professor que ensina Matemática, uma vez que a condução desse espaço pauta-se na (re)significação de sua prática pedagógica.

\section{Referências}

Bahia. (2019). Documento Curricular Referencial da Bahia para Educação Infantil e Ensino Fundamental. Secretaria da Educação. Superintendência de Políticas para Educação Básica. União Nacional dos Dirigentes Municipais da Bahia. União Nacional dos Dirigentes Municipais de Educação. Salvador: Secretaria da Educação.

Franzoni, G. G. \& Panossian, M. L. (1999). O laboratório de matemática como espaço de aprendizagem. In: Moura, O. O estágio na formação compartilhada do professor: retratos de uma experiência. São Paulo: FEUSP.

Grando, R. C. (2004). O jogo e a Matemática no contexto da sala de aula. Paulus, Coleção Pedagogia e Educação.

Justo, J. C. R. \& Dorneles B. V. (2012). Formação continuada em matemática de professores polivalentes - dois estudos sobre resolução de problemas aditivos. Revista Eletrônica de Educação Matemática, Florianópolis, 7(1), 78-94.

Lopes, J. A. \& Araújo, E. A. (2007). O Laboratório de Ensino de Matemática : Implicações na Formação de Professores. Zetetiké. 15(27). Cempem/FE/Unicamp. Recuperado de: https://www.fe.unicamp.br/revistas/ged/zetetike/article/download/2420/2182.

Lorenzato, S. (2006). O Laboratório de Ensino de Matemática na Formação de Professores. Autores Associados.

Machado, N. J. (1989). Matemática e realidade. (2a ed.), Cortez.

Nascimento, S. K. O. S; Souza, I. S \& Silva, A. J. N. (2020). O professor que ensina matemática e a resolução de problema: um olhar para as vivências em sala de aula dos anos finais do ensino fundamental. BrazilianJournal of Development, Curitiba, 6(9), 64255-64267. https://brazilianjournals.com/index.php/BRJD/article/view/16001/13105.

Pacheco, J. A. \& Flores, M. A. (1999). Formação e avaliação de professores. Porto, Porto Editora LDA, Coleção Escola e Saberes, n¹6.

Silva, A. J. N. (2014). A ludicidade no laboratório: considerações sobre a formação do futuro professor de matemática. Curitiba: Editora CRV.

Silva, A. J. N. (2020a). O Laboratório de Educação Matemática e a Formação Inicial de Professores de Matemática. Revista Internacional Educon. 1(1), e20011001, 2020a. 10.47764/e20011001. https://grupoeducon.com/revista/index.php/revista/article/view/14.

Silva, A. J. N. (2020b). Laboratório de Estudos e Pesquisas em Educação Matemática do Campus VII da UNEB: espaço de formação e desenvolvimento do conhecimento lúdico e pedagógico do conteúdo. In: Vieira, André Ricardo Lucas; Silva, Américo Junior Nunes da. (Org.). O futuro professor de matemática: vivências que intercruzam a formação inicial. 01ed.Porto Alegre: Editora Fi, 36-59.

Silva, A. J. N. da. (2021). Professores De Matemática Em Início De Carreira E Os Desafios (Im)Postos Pelo Contexto Pandêmico: Um Estudo De Caso Com Professores Do Semiárido Baiano: doi.org/10.29327/217514.7.1-5. Revista Ibero-Americana De Humanidades, Ciências E Educação, 7(1), 17. http://periodicorease.pro.br/rease/article/view/430.

Silva, A. J. N; Souza, I. S \& Prado, I. S. (2020). O ensino de Matemática nos Anos Finais e a ludicidade: o que pensam professora e alunos? Revista Educação Matemática Debate. 4(10). https://www.periodicos.unimontes.br/index.php/emd/article/view/1672/2590.

Smole, K. S.; Diniz, M. I. \& Milani, E. (2007). Jogos de matemática de $1^{\text {o }}$ a $5^{\circ}$ ano. Artmed.

Sousa, L. P.; Souza, Z. S \& Rolim, C. L. A. (2015). Ensino de Matemática nos anos iniciais: contribuições do laboratório de educação matemática na formação docente. In: XII Congresso Nacional de Educação. Recuperado de: Disponível em: https://educere.bruc.com.br/arquivo/pdf2015/17483_9730.pdf.

Tardif, M. (2011). Saberes docentes e formação profissional. (12a ed.), Petrópolis, RJ:Vozes.

Turrioni, A. M. S \& Perez, G.(2009). Implementando um laboratório de educação matemática para o apoio na formação de professores. In: LORENZATO, Sergio. O Laboratório de Ensino de Matemática na Formação de Professores. (2a ed.), Autores associados. 
Research, Society and Development, v. 10, n. 2, e28510212697, 2021

(CC BY 4.0) | ISSN 2525-3409 | DOI: http://dx.doi.org/10.33448/rsd-v10i2.12697

Vieira, E. S., \& Silva, A. J. N. (2020). Dominó Fracionário: uso do material didático para o ensino de frações. Mundo Livre: Revista Multidisciplinar Discente, 6, 134-146. https://periodicos.uff.br/mundolivre/article/view/43270. 